American J. of Engineering and Applied Sciences 3 (3): 501-508, 2010

ISSN 1941-7020

(C) 2010 Science Publications

\title{
Privacy and Social Interaction in Traditional Towns to Contemporary Urban Design in Iran
}

\author{
Samira Ramezani and Shima Hamidi \\ Department of Architecture and Urban Design, Faculty of Built Environment, \\ University Technology Malaysia, 81310, UTM, Johor, Malaysia
}

\begin{abstract}
Privacy as an inherent feature of Iranian culture is evident in formation of Iranian traditional towns. Put differently, attention to the inside was one of the most desirable principles in Iranian traditional architecture as well as urbanism. However, privacy did not lead to isolation in Iranian culture and social contact was also of a great importance to Iranians. Problem statement: Although sense of privacy as well as sociality are still parts of Iranian culture and have been transferred from one generation to another, contemporary cities do not meet these needs. Newly designed cities have encountered a decrease in sense of privacy and social interaction among residents. Approach: Coming up with an alternative solution for urban design which would respect this culture in cotemporary cities while matching the new life style of people, would contribute to achieving a sustainable urban form one of the principles of which is social and cultural sustainability. This article, therefore, aimed to reveal how the traditional urban form considered resident's needs of privacy as well as social interaction simultaneously and how to regenerate sense of privacy and social contact in the contemporary neighborhoods in Iran. The method used in this study was analysis of data gathered through library study. Results: This study suggested that the existence of transitional spaces in traditional cities was the main reason for simultaneous generation of privacy and social interaction, thus, a contemporized form of those spaces in contemporary residential areas might help in increasing the aforementioned attitudes in contemporary cities. Conclusion: This study has an important implication for those involved in development of new neighborhoods. It would be hoped that this study triggers creative future design solutions that would consider the socio-cultural issues in designing as well as planning processes.
\end{abstract}

Key words: Urban form, social sustainability, socio-cultural issues, neighborhood design

\section{INTRODUCTION}

The physical construct of Iranian traditional Cities was associated with culture of the society. In the process of formation and evolution of Iranian cities, whether they were formed in an organic way or not, thoughts, beliefs and emotions of the public were manifested. Accordingly, the cultural principle of privacy was one of the determinant factors in the aforementioned process which is still evident in the hierarchy of spaces in old contexts. One of the main reasons for the existence of the sequential space in Iranian houses and cities is the introverted personality of Iranians. However, different factors have affected the formation and development of Iranian cities and while each factor is significant no single one can be held individually responsible in this process (Kheirabadi, 2000). A host of researchers have tried to introduce a mere climatic reason for appearance of this attribute in traditional houses and urban form but such an ideology ignores socio-cultural factors which have evidently affected the form of traditional houses and towns. Those socio-cultural factors are, for instance, manifested in the different typologies of houses in the same climatic region (Memarian, 2005).

On the other hand, referring to the religious philosophy of privacy or Hijab as a reason for appearance of this attribute in traditional cities seems superficial when considering traces of sequential space in older towns such as Persepolis which existed one thousand years before the advent of Islam. Indeed, the abovementioned city pattern is rooted in Iranian's culture and sense of privacy which is magnified with the Islamic rules emphasizing the necessity of Hijab (Haji Ghassemi, 1999).

Corresponding Author: Samira Ramezanị, Department of Architecture and Urban Design, Faculty of Built Environment, University Technology Malaysia, 81310, UTM, Johor, Malaysia 
Put differently, the desire to have a distinguishable spatial domain which is the innate quality of human beings was very important to Iranians. Spatial domain in architecture and urban design is usually defined in two forms of public and private. Undoubtedly private space is the territory of one or a few number of people while public realm belongs to all. However the main point is the space between these two realms and the way they are connected in traditional cities, especially in residential districts. Furthermore, a high level of social interaction among neighbors in spite of the existence of introversion in Iranian culture and the way form of traditional towns offered this juxtaposition, is worthy of reflection.

With the advent of modernism in Iran, superficial adaptation of western Ideas devastated and disregarded admirable characteristics of traditional urban form thus ignoring the culture and needs of residents. Gridded street pattern, as a result, sacrificed privacy and social interaction which were an essential in residential areas.

At the present time, we have to compensate for the unsatisfactory actions of the past in the domain of contemporary architecture and urban design by looking back to our traditional cities, extracting their honorable characteristics and contemporizing them in such a way that would match our present lifestyle and would provide convenience for the residents. As the aim of all societies is to achieve a sustainable society one of the principles of which is social sustainability, this study makes an effort to create a more sustainable neighborhood environment by utilizing the principles of social sustainability discussed in this study such as designing by consideration of spiritual and cultural enrichment as well as encouraging and increasing social interaction.

\section{MATERIALS AND METHODS}

The method used in this research is analysis of data gathered through library study. The literature on definition of privacy and its relation to social interaction, the way form of Iranian traditional towns created an environment respecting these attributes and how modernism affected these attributes are reviewed and analyzed. The study lasts with proposing an alternative design solution based on the features and attributes extracted from literature.

Privacy and its relation to social interaction: Factors such as privacy, personal space and territorial behavior affect perception of convenience and quality of environment (Lang, 1987). The need to have privacy is common amongst human beings and helps in meeting other needs of security, affiliation and esteem (Altman, 1975). However, the way people express this need and the way to achieve it is different in different societies (Altman and Chemers, 1984).

Definitions of privacy have one characteristic in common. The important point in all those definitions is the ability of one person or a group of people to control audio-visual and olfactory interaction with other people (Lang, 1987). In other words, privacy and social interaction have a close relationship. Rapoport (1977) defines privacy as the ability to control social interaction and being able to choose the desired rate of social interaction. Hence, privacy should not lead to isolation (Schwartz, 1968). A number of theorists have referred to the human's need of territory as a need to manage the bound between self and others. Altman (1975) further refers to spatial territory as not only a place to provide privacy but also a place to stabilize social contacts. Lang (1987) mentions that if the social needs of people are in balance with the sense of independence provided by privacy, social interaction will be easier. Spaces that are indefinite and it is not clear whether they are public or private allow less control on social interaction and decrease it as a result. Physical privacy is the prerequisite for social behaviors. In an environment with physical privacy a wider range of personal choices occur. One of the ways to achieve privacy is to avoid contacting with others while another way is to control spatial territory. If the spatial territory of residents in a space of joint ownership has clear boundaries, the rate of social interaction among neighbors is higher than when privacy is achieved through avoidance of contact with others (Lang, 1987).

However, the type and the rate of desired privacy depend on cultural context. Territorial behavior in human beings is still dependent on cultural criteria even if it has a biological basis (Ardrey, 1966).

Structure of Iranian traditional cities: Scrutinizing the context and structure of Iranian traditional cities reveals a general rule. In all those towns, Bazaar, usually taking a linear shape, acted as the spinal column of city and continued towards the main gates of town. Passageways were in fact branches of the linear Bazaar which connected the city centre to neighborhood centre (Karimi, 1997).

Neighborhood centre was an urban public space in neighborhood scale and consisted of Mosque, water reservoir, public bath and a flexible open space which was used for religious ceremonies as well as daily social interactions (Soltanzadeh, 1998). This centre was shared by the people residing in the nearby 
houses and indeed it was acting as a semi-public space and there were a number of gates through which the traffic of aliens was controlled by the residents in certain cases such as quarrel among different neighborhoods.

Neighborhood centre was leading to a semi-private open space, which belonged to a few number of households, through secondary passageways. The most rate of social interaction among neighbors especially housewives took place in this space and residents had a sense of belonging and attachment towards it. This semi-private space was connected to houses by means of narrow passageways (Tavassoli, 1983). In fact, the Iranian traditional urban form followed a sequence. Figure 1 shows the structure of the city of Naien, one of the Iranian traditional towns.

A considerable point worthy of mentioning is the presence of this attribute in a smaller scale inside the house. In an Iranian house the entrance arrangements were extremely important. Iranian houses were seldom more than single storey and the surrounding walls were high and thick. Mostly blank Openings, where necessary, were small and placed above eye level to prevent passers-by from looking into the house. Generally, the presence of a single heavy door was the only clue of habitation within (Memarian and Brown, 2006). But the entrance did not, in any condition, allow a direct view of the private quarters of the house. Its position therefore was accurately calculated and in some cases it was located totally away from the courtyard (Soltanzadeh, 2004). Selection of private quarters could be determined, or reinforced by the shape of the passageway which connected the entrance to the courtyard. The intention was to block direct sight to the interior. In a linear form the passageway usually lead to a corner of the courtyard, where there was no household activity (Memarian and Brown, 2006) (Fig. 2).

Planning of the entrance was as carefully considered as that of the courtyard itself. In the Iranian houses vestibule or Hashti was an important part of entry sequences as well. This was designed as a stopping point and could be used as a temporary reception room for those who did not need to enter the guest room. This pattern is by no means accidental but a carefully considered response to the balance needed between hospitality and privacy (Memarian and Brown, 2006).

Modernism and formation of contemporary cities in Iran: The historical revolution of traditional cities during thousands of years encountered an abrupt transformation about hundred years ago. One of the most important causes of this event was the journey of king of Iran to western countries witnessing the appearance of the ideology of Modernism and its upshots. Acquaintance of the Iranian king with this concept led to his desire to transform the traditional society to a modern one in all aspects (Madanipour, 1998). On the other hand, discovery of petroleum in Iran caused great changes in social and economical structures of the society. While government was economically dependent to the citizen's tax and, as a result, there was a kind of evenness between government and the public, discovery of petroleum thoroughly disturbed the balance. Petroleum Revenues released the government from dependency to the productive economy and appeared as a facilitating means of converting the traditional society to a modern one.

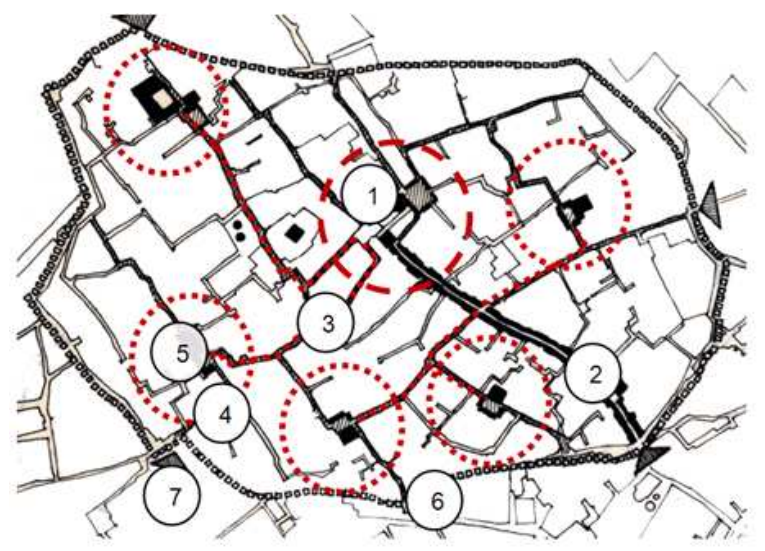

Fig. 1: The structure of old context of Naien, one of the historical cities of Iran. (1) City centre; (2) Bazaar; (3) Main route; (4) Neighborhood area; (5) Neighborhood centre; (6) city wall; (7) Main gates. Iranian traditional urban form follows a spatial sequence starting from Bazaar (public space), followed by neighborhood centre (semi-public), the semiprivate space owned by a few number of households and ending to the house as a privately owned space (Tavassoli, 1990)
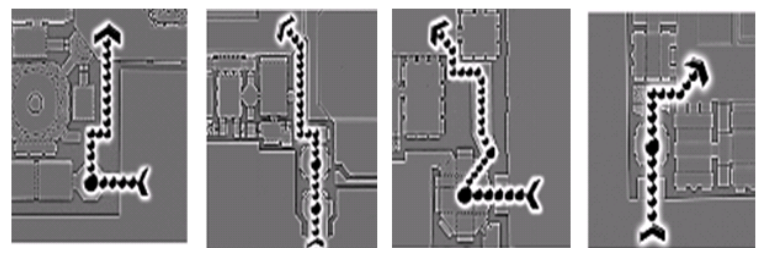

Fig. 2: The indirect path in the entrance space blocks a direct view towards the private parts of the house 


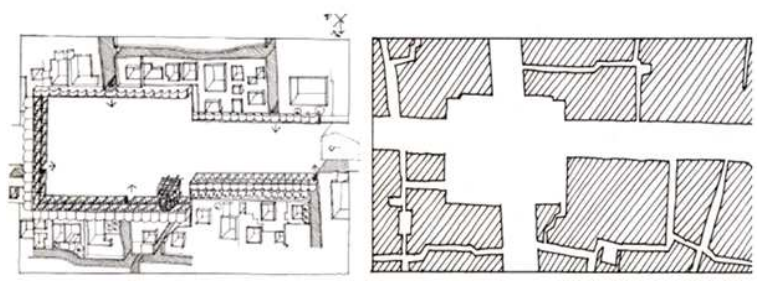

Fig. 3: Shah Tahmasb Square (left) in Yazd: the functionalist concept of modernism has changed the urban squares to car oriented junctions (right) (Tavassoli, 1990)

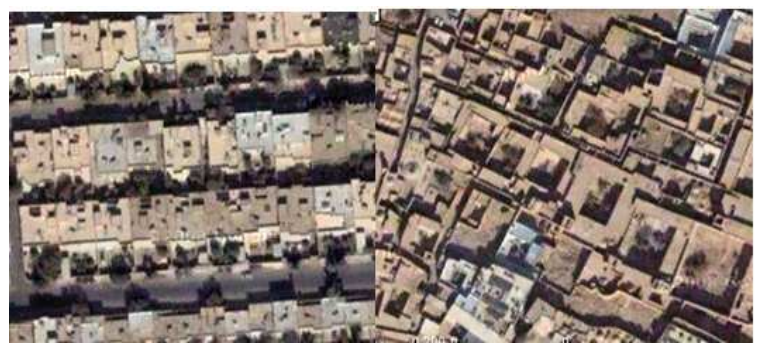

Fig. 4: Aerial view of traditional (left) and contemporary (right) urban fabric of Yazd shows the deterioration of spatial sequence in Iranian traditional cities. (Left): Old urban fabric, (Right): New urban fabric Source: Google Earth

Indeed, at that time, they were the public who expected government to carry out executive urban projects while traditional towns were formed in an organic way based on experiential knowledge of the public and without a direct supervision of government (Habibi, 1996).

Modernization of urbanism in Iran starts from Tehran (Habibi, 1996). The first manifestation of modernistic movement in Iran was evident in practicing the ideas of international style which was developing in the west (Marefat, 2008). The first action taken by the government in the domain of urban planning was approving the law of widening and extension of roads in 1933 which allowed the government to reform the historical organic context of city and demolish some parts when necessary so as to provide an easy and fast access to all corners of the city for the imported automobile. Figure 3 illustrates an example of such changes in the fabric of Iranian towns.

One of the in 1937 the first urban plan was offered by the French for city of Tehran following the pattern of industrial city. The most significant characteristics of this plan included elimination of city gates, demolition of some neighborhoods for the purpose of erecting official buildings such as Banks and ministries, shift of the centre point of city from Bazar to the newly established avenues and establishing important urban spaces around them (Habibi, 1996).

Consequently, there was no consideration of the sequence in urban form that existed in traditional cities. Utilizing the scheme suggested by Hosman (1991) who encouraged wide and perpendicular gridded street pattern, street was introduced not as a complementary element and part of a continuous urban fabric but as an element dominating the whole system of urban spaces. Neighborhoods were segregated by wide urban roads and appeared as disconnected islands. Figure 4 shows the changes in street patterns of Yazd, one of the traditional cities in Iran.

These changes did not only happen in the general fabric of the city. The concept of modernism which followed a functional approach broke up the structure of traditional neighborhoods as well by applying monofunctional zoning. In this period neighborhood got an outward looking appearance and the service spaces which resided in the inner layers of the neighborhood moved to outer layers to provide easy access for cars (Habibi, 1996). This extraversion happened even inside the house. In fact the outward looking architecture superseded the inward looking one and the windows looking towards the streets broke up the structure of the traditional houses which showed a sensitive distinction between inside and outside. In fact, for the first time in the history of urbanization in Iran, the townscape was transformed not based on the revolutionary thoughts and needs of Iranians themselves but on the invading concepts (Tavassoli, 1997).

Lack of privacy and social interaction in contemporary cities: Although government succeeded in creating almost modern cities with the aforementioned attributes by means of physical reformation of traditional towns, changing the culture of a traditional society being developed during thousands of years and transferred from one generation to another was not an easy task. Fast development of Iranian cities has produced spaces without cultural values. This is inevitable because culture needs time to develop. In the Iranian society, in spite of all rapid social and economic changes, culture still plays an important role in shaping the living environment. In the modern urban planning system of Iran, quantitative needs have overcome the qualitative importance of a living environment (Ferdowsian, 2006).

Residing in newly designed neighborhoods with wide streets and direct view of strangers was unfamiliar and unsatisfactory for Iranians as it didn't offer sense of privacy and security. Social interaction among 
neighbors decreased as well, as a result of elimination of the semi private and semi public urban spaces.

After about hundred years people are not still used to the new situation and do not have a sense of belonging to their newly designed neighborhoods which lacks sense of privacy and doesn't allow social interaction to take place among neighbors. What has been ignored in modern urban life are very simple aspects of relationships between people to people and people to their living environment. As a result, Sense of belonging is an aspect that is lost in modern life (Ferdowsian, 2006).

In fact, one of the greatest problems in contemporary urban design in Iran especially in residential areas is the abrupt connection of private space with the public space. Going outside the house, residents of a $12 \mathrm{~m}$ street, which is quite common in contemporary cities, suddenly encounter the high traffic of public space. In such a car oriented neighborhood, residents do not experience a sense of belonging to their living environment in that the outdoor spaces previously belonging to them has become the territory of automobiles.

\section{RESULTS}

Hierarchical space and its importance in Iranian cities: Review of literature revealed that sense of privacy and its juxtaposition with social interaction in Iranian traditional cities was provided by transitional spaces. As demonstrated above, the hierarchy of spaces in Iranian traditional cities starts with a public space and is continued with a semi-public, semi-private and at last a private space (Fig. 5). The transitional spaces (semi-public, semi-private) in the neighborhood helped the residents to manage the rate of social interaction and therefore allowed for meeting both needs of privacy as well as social contact.

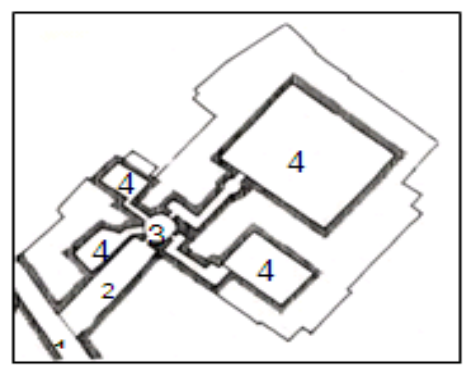

Fig. 5: Hierarchical space in a neighborhood in Yazd: (1) public space; (2) semi public space; (3) semi private space; (4) private space (Tavassoli, 1990)
In other words, the traditional city has a structured hierarchy of public and private spaces. There are no leftovers. The in-between or the transitional space is defined spatially and functionally Encompassing walks make good neighbors. Each person is assured a private retreat outside public view and removed from the clamor of the streets. Those public spaces (streets, Bazaar, mosque, schools and the caravansaries-the inns and storehouses) serve a complementary function to maximize social contact. What is public and what is private is separate but totally interdependent domains (Carruthers, 1984).

Put differently, the main functions of creating those semi-public and semi-private spaces, in traditional towns, other than providing sense of privacy can be summarized as follows:

- It offered the residents a sense of security and belonging

- It allowed the residents to act as they desired in the private spaces without intrusion of aliens while having a semiprivate space for gathering with nearby neighbors and a semi public space for more social interactions therefore making them able to manage their desired rate of social contact (Tavassoli, 1990)

\section{DISCUSSION}

Towards creating a socially sustainable environment in contemporary cities in Iran: Having the concept of social sustainability in mind magnifies the need for reconsideration of contemporary urbanism in Iran. The concept of social sustainability includes a broad range of topics demonstration of which is out of the scope of this study but among those topics are social interaction as well as spiritual and cultural enrichment (Kunz, 2006). These two topics are our concerns in contemporary urbanism in Iran while they were respected in traditional cities. Furthermore, the concept of social sustainability is contextual, which means criteria for social sustainability in two different reigns are not necessarily the same or may be of different importance (Kunz, 2006).

It is neither desired to duplicate the traditional urban form nor is it wished to ignore new life style of people. The authors would like to argue that by considering the cultural issue of privacy and its juxtaposition with sociality as another cultural issue in Iran, the way the transitional spaces especially in the neighborhoods' allowed for satisfying both of these cultural needs and the new lifestyle of people we would be able to come up with alternative solutions for 
contemporary urbanism so as to achieve a socially sustainable environment that according to literature provides a balance between tradition and innovation (Konning, 2001).

This study suggests that adopting the transitional spaces(semi public and semi private) in traditional urban form, contemporizing and using them in contemporary neighborhoods' would revitalize inanimate contemporary neighborhoods' in Iran by regenerating both, privacy and social interaction and therefore leads to a socially sustainable environment that respects the culture of society members. This is also worthy of attention that this transitional space has also been suggested in western literature. A study on social sustainability, in a preliminary list of formal indicators of social sustainability, refers to transitional spaces (softness) which is explained to be the Continuity of the 4 steps transition: private, semi/private, semi/public, public (Porta, 2001).

This transitional space had also been discussed before by Newman (1972) as one of the attributes of a defensible space which he defines as a hierarchy of spatial systems including real and symbolic hindrances, defined permeable realms and feasibility of more control which, altogether, make an environment under the control of residents. According to him this attribute can be achieved by means of symbolic hindrances such as texture of surface, stair, light tableaus and projection or real hindrances. He further discusses that creation of these areas is an effective way in that it creates subdivisions in residential areas each of which can meet especial needs of residents. Newman (1972) used a graph to elaborate his aforementioned hypothesis (Fig. 6).

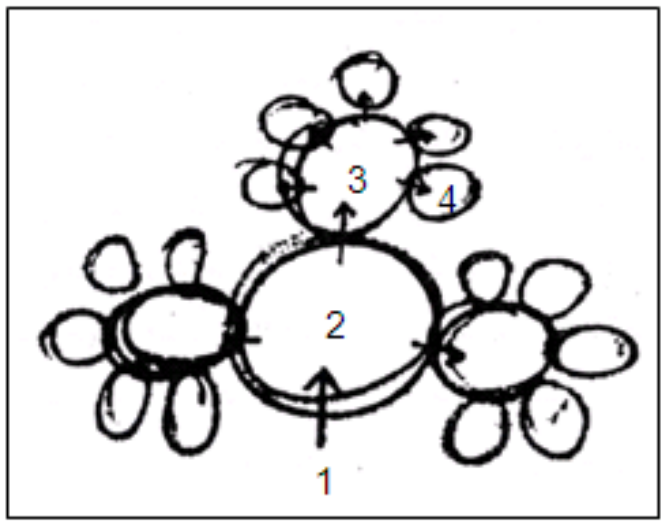

Fig. 6: The hierarchy of spaces suggested by Newman (1972) for enabling residents to control their territory. (1) public space; (2) semi public space; (3) semi private space; (4) private space
Jacobs (1992) mentions that when supervision is provided through windows opened towards the street and there is a possibility for fulfillment of activities and functions such as temporary parking for cars in front of the house, pedestrian movement in short routes, meeting in the intersections and social interaction among neighbors; street becomes a semi public space which is under control of the residents although everyone has the right to enter it. Moreover, a number of researches have shown that people residing in cal de sacs know each other more than those living in main roads which are public (Lang, 1987).

Considering the points in the abovementioned literature and in order to achieve the goals of this study the authors suggest a rough draft of a small scale neighborhood in an imaginary site (Fig. 7). Creating a hierarchy of access through changes in width and length of streets as well as provision of cal de sacs by which traffic would be more manageable and effective design of house in terms of its location with regards to other houses and the street are some objectives in this draft. Furthermore, creation of transitional spaces with the goal of controlling the spatial territory is supposed to achieve the following objectives:

- Generating sense of security among residents due to the possibility to control activities and through provision of windows looking towards the street

- Increasing residents' sense of ownership and belonging to their living environment (although the semi private and semi public space do not officially belong to them, residents would know them as their belongings)

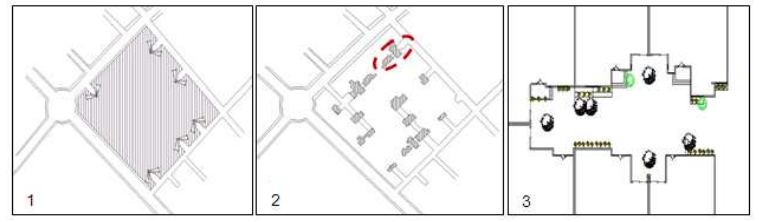

Fig. 7: The suggested scheme. (1) The first draft that shows separation of semi public and public space; (2) Cal de sacs provide a semi public space which is the territory of a number of houses. The hatched area shows a semi private space owned by $2-4$ houses in a cal de sac; (3) Enlarged plan of one of the cal de sacs and the way recession in the plan of houses at the entrance space provides a semi private space for 2-4 h in a cal de sac. Source: Authors own data 
- Creating potentiality for social interaction through:

- Provision of temporary parking for cars which can also be used as a place for children to play when there is no car parked

- Creation of short routes which encourage walking

- Effective design of the entrance space to create a place used for meeting others while providing privacy

\section{CONCLUSION}

Sense of privacy and Social interaction which are perceived to have a relation in the theories of architecture and urban design were well respected in traditional urbanism in Iran. The juxtaposition of these two criteria, associated with the culture and characteristics of Iranians, in traditional towns was achieved through provision of transitional spaces which allowed the residents to control their desired rate of privacy as well as social contact with their neighbors through a sensitive separation of private and public realm. This is while residents of contemporary cities in Iran suffer lack of privacy and social interaction especially in the newly designed residential areas.

In an attempt to create a socially sustainable environment which considers the socio-cultural needs of residents this study suggests a contemporized form of spatial sequence in contemporary cities with an especial emphasis on residential areas. In the suggested scheme a hierarchy of access through changes in width and length of streets as well as provision of cal de sacs and windows looking towards it so as to provide a semi public space as well as a sensitive design of entrance space for creation of a semi private space in front of houses are main principles. However, the rough draft suggested in this study is not the mere solution and creative future design solutions would contribute to achieving the goals of this study.

\section{REFERENCES}

Altman, I. and M. Chemers, 1984. Culture and Environment. 2nd Edn., Cambridge University Press, ISBN: 0-521-31970-6, pp: 337.

Altman, I., 1975. Environment and Social Behavior. Monterey, Ca. Brooks/Cole, ISBN: 0818501685, pp: 256.

Ardrey, R., 1966. The Territorial Imperative. Atheneum, New York, ISBN: 9780689100154, pp: 390.

Carruthers, K.D.B., 1984. Architecture is space: The space positive tradition. J. Architect. Educ., 39: 17-23. http://www.jstor.org/stable/1424783
Ferdowsian, F., 2006. Modern and Traditional Urban Design Concepts and Principles in Iran. Simaye Danesh Publication, Tehran, ISBN: 964-5693-87X, pp: 330.

Habibi, M., 1996. De la Cit e Ala Ville: Analys Historiquede la Conception Urbaine et Son Aspect Physique (Az Shar Ta Shahr), Tehran, University of Tehran Press, ISBN: 964-03-5206-3, pp: 252.

Haji Ghassemi, K., 1999. Searching for meaning in Persian Islamic architecture. Proceeding of the Annual MESA Conference on Current Trends in Contemporary Iranian Culture, Washington, DC., pp: 1-1. http://ilexfoundation.org/confer/mesa.html

Hosman, L.A., 1991. The relationships among need for privacy, loneliness, conversational sensitivity and interpersonal communication motives. Commun. Rep., 4: 73-81.

Jacobs, J., 1992. The Death and Life of Great American Cities. Vintage, New York, ISBN: 9780679741945, pp: 458.

Karimi, K., 1997. The spatial logic of organic cities in Iran and the United Kingdom. Proceeding of the Space Syntax 1st International Symposium, London, pp: 1-17.

Kheirabadi, M., 2000. Iranian Cities: Formation and Development. 2nd Edn., 1st Syracuse University Press, New York, ISBN: 0-8156-2860-9, pp: 132.

Konning, J., 2001. Social sustainability in a globalizing world-context, theory and methodology explored. More on Most: Proceedings of an Expert Meeting, Nov. 22-23, The Hauge, The Netherlands, pp: 1-30. http://spitswww.uvt.nl/web/telos/documents/konin g\%20telos\%20paper.pdf

Kunz, J., 2006. Social Sustainability and Community Involvement in Urban Planning. University of Tampere, Finland, ISBN: 951-44-6676-4, pp: 118.

Lang, J., 1987. Creating Architectural Theory: The role of the Behavioral Sciences in Environmental Design. Van Nostrand Reinhold, New York, ISBN: 0442259816, pp: 352.

Madanipour, A., 1998. Tehran: The Making of a Metropolis. Academy Press, ISBN: 9780471957799, pp: 302.

Marefat, M., 2008. Modernizing and De- Modernizing: Notes on Tehran. Architecture and Urbanism in the Middle East: Viewpoints special edition. The Middle East Institute. http://www.urbanharmony.org/en/download/resear $\mathrm{ch} /$ files/Architecture_and_Urbanism_in_the_Middl e_East.pdf

Memarian, G.H. and F.E. Brown, 2006. The Shared Characteristics of Iranian and Arab Courtyards. In: Courtyard Housing, Past, Present and Future, Edvard, B. et al., (Eds.). Taylor and Francis, ISBN: 0415-26272-0, pp: 21-30. 
Memarian, G.H., 2005. A Journey in Theories of Architecture. Sourosh Danesh Publication, Tehran, Iran, ISBN: 964-96113-5-5, pp: 576.

Newman, O., 1972. Defensible Space: Crime Prevention through Urban Design. Macmillan, New York, pp: 264.

Porta, S., 2001. Formal indicators: Quantifying the contribution of form to urban (social) sustainability. Proceeding of the Conference on Walking the 21st Century, Perth, Australia, pp: 1-12. http://www.dpi.wa.gov.au/mediafiles/walking_21c entconf01apaper_porta.pdf

Rapoport, A., 1977. Human Aspects of Urban form. Pergamon Press, New York, ISBN: 0080179746, pp: 438.

Schwartz, B., 1968. The social psychology of privacy. Am. J. Psychol., 73: 741-752. PMID: 5695022

Soltanzadeh, H., 1998. Urban spaces in Historical Urban Context of Iran. Pajuheshhaie Farhangi Publication, Tehran, Iran, ISBN: 964-6269-98-2, pp: 215.
Soltanzadeh, H., 2004. Entry spaces in the traditional architecture of Iran. Pajuheshhaie Farhangi Publication, Tehran, Iran, ISBN: 964-6269-95-8, pp: 236.

Tavassoli, M., 1983. City Planning in the Hot and Dry Climate of Iran. In: Design for Arid Regions, Golany. G.S. (Ed.). Van Nostrand Reinhold Company, ISBN: 0442229240, pp: 400.

Tavassoli, M., 1990. Principles and Techniques of Urban Design in Iran. Urban Planning and Architectural Research Centre of Iran, Ministry of Housing and Urban Development, Iran, ISBN: 964-6301-01-01, pp: 125.

Tavassoli, M., 1997. Urban Space Design Criteria. Urban Planning and Architectural Research Centre of Iran, Ministry of Housing and Urban Development, Iran, ISBN: 964-6301-002, pp: 148. 